\title{
A scale model investigation of the circulation in reservoirs
}

\author{
K. H. M. ALI, T. S. HEDGES \& R. B. WHITTINGTON
}

\section{Dr R. A. Falconer, University of Birmingham}

The Authors have presented useful data to help clarify the water circulation patterns and degree of mixing in two typical reservoirs. In a similar study I developed a two-dimensional mathematical model capable of indicating the depth-averaged velocity field and the corresponding jet-forced circulation in reservoirs of a similar topographical shape. ${ }^{9}$ The results and conclusions obtained in the study were generally in good agreement with those of the Authors except for the conclusion in $\$ 81$. As it can be argued that the degree of mixing is predominantly dependent on the velocity gradients which in turn are proportional to the jet momentum flux, it seems reasonable to conclude that the overall degree of mixing must be proportional to the net inlet momentum flux. Thus, applying these arguments to a comparison of two identical reservoirs, one having a single nozzle inlet of area $A$ and the other having two perpendicular nozzles each of area $A$ and with the same net throughflow in both reservoirs, one would expect the overall mixing characterist ics in the first reservoir to be superior. This reasoning was supported by comparing the numerical results in Figs 25 and 26, which relate to the two different nozzle inlet configurations mentioned. (For clarity, velocities greater than $2 \mathrm{~m} / \mathrm{s}$ are not included in Figs 25 and 26.) The larger momentum influx associated with the single jet inlet in Fig. 25 resulted in larger velocities and velocity gradients throughout the reservoir. Consequently in my opinion the Authors might not have concluded that the mixing was markedly improved by the introduction of twin nozzle inlets if the same nozzle area had been used in their comparisons between Figs 10(a) and 10(b) and 13(a) and 13 (b) respectively.

87. In the case of the single jet inlet in reservoir 4, do the Authors think that the circulation velocities and the degree of mixing might have been increased if the nozzle inlet 6 had been located at the intersection of B and 15 in Fig. 1 and directed towards the outlet 8 ? From reference 9 it was concluded that in the case of a single nozzle inlet the degree of mixing was improved by directing the nozzle towards the centre of mass of the body of water.

Mr P. Minton, Imperial College of Science and Technology, and Mr S. J. Robinson, Thames Water Authority

The Authors have made a useful contribution to the scant literature available on reservoir circulation. The Paper is particularly welcome to others who are modelling reservoir flows.

89. As a check on the validity of experiments which we are performing, using buoys to measure depth-averaged velocities, we have constructed a model of a similar shape to

Paper published: Proc. Instn Civ. Engrs, Part 2, 1978, 65, Mar., 129-161. 


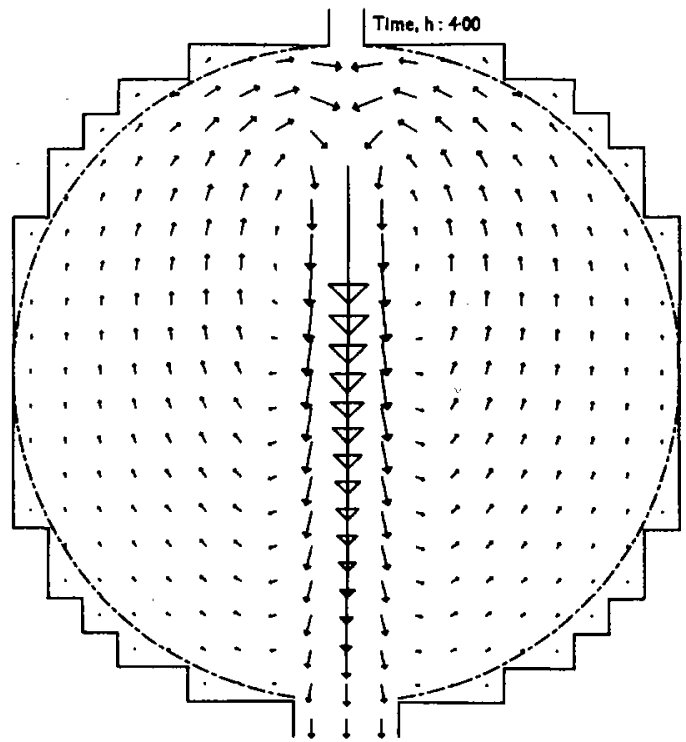

Fig. 25. Computed velocity field for a shallow jet inlet

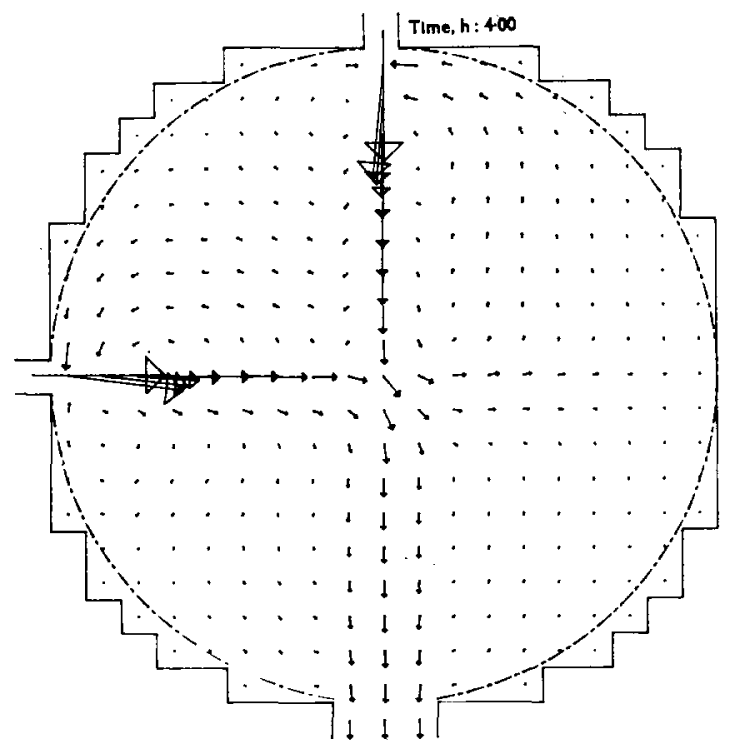

Length scale - $80 \mathrm{~m}$ Velocity $\longrightarrow 0.08 \mathrm{~ms}$ Iniciat depth $24.0 \mathrm{~m}$ let inflow $\quad 240 \mathrm{~m}^{3} / \mathrm{s}$ Jet velocity $\quad 0.60 \mathrm{~m} / \mathrm{s}$ Chezy value 56.6 metric Weir outflow $240 \mathrm{~m}^{3} / \mathrm{s}$ Depth of jet $5.0 \mathrm{~m}$

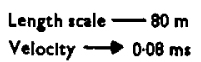

Initial depth $24.0 \mathrm{~m}$ jet inflow $120 \mathrm{~m}^{3} / \mathrm{s}$ jet velocity $\quad 0.30 \mathrm{~m} / \mathrm{s}$ Chezy value 56.6 metric Weir outflow $240 \mathrm{~m}^{3} / \mathrm{s}$ Depth of jet $5.0 \mathrm{~m}$

Fig. 26. Computed velocity field for two perpendicular shallow jet inlets 
that of reservoir 4 described in the Paper. Our model has the same vertical scale but a horizontal scale of 116:1, which is approximately twice that of the main model described in the Paper. The resulting flow patterns (Figs 27-29), which correspond respectively to Figs $6(\mathrm{~b}), 8(\mathrm{a})$ and $8(\mathrm{~b})$, show a gratifying similarity in the flow patterns of the two models. In both cases the area of secondary circulation in the south-east corner of the reservoir increases with increasing jet momentum flux, although our model always indicates a rather larger area of secondary circulation than is shown by the figures in the

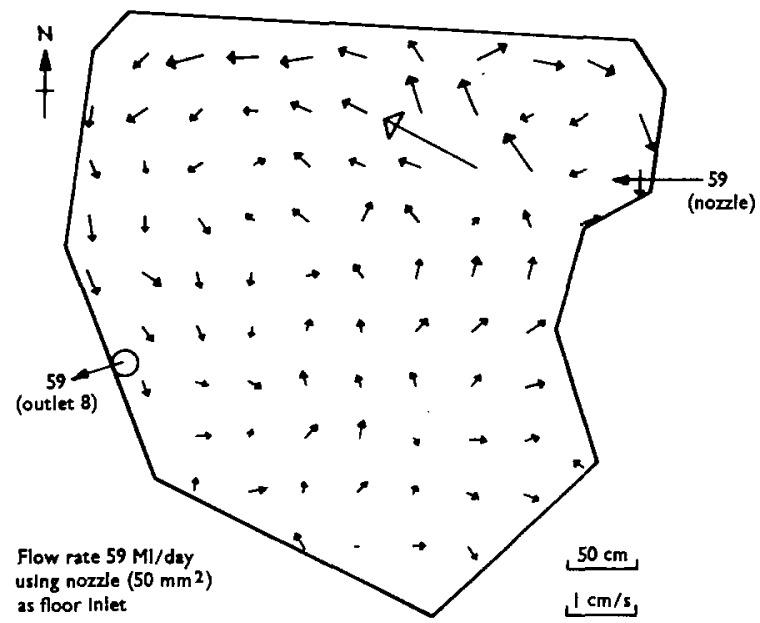

Fig. 27. Depth-averaged velocity field for reservoir 4

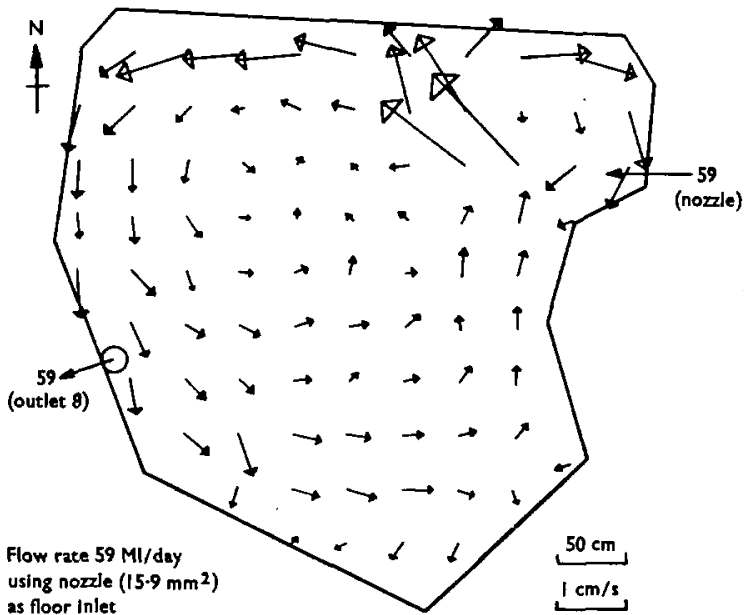

Fig. 28. Depth-averaged velocity field for reservoir 4 


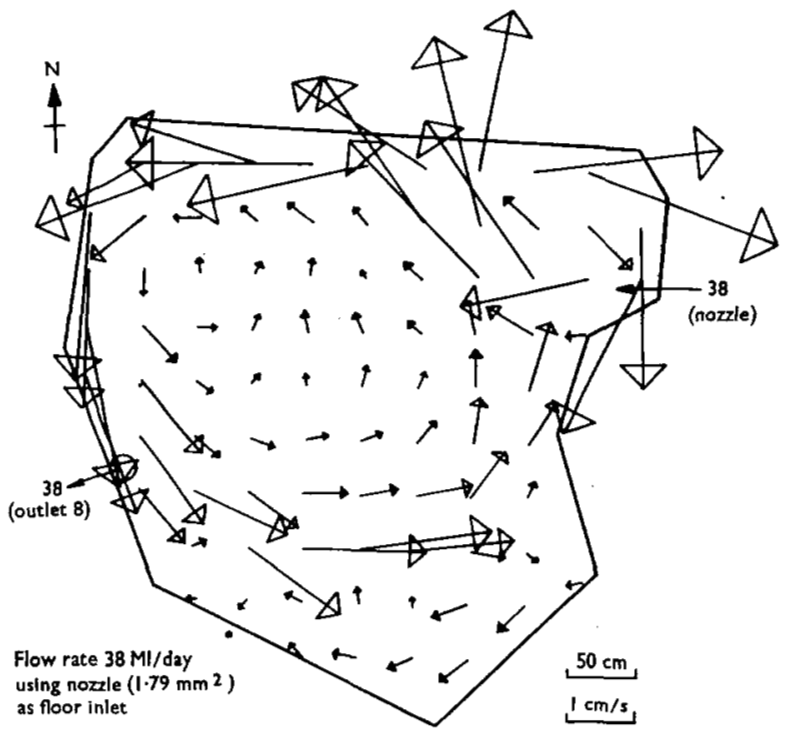

Fig. 29. Depth-averaged velocity field for reservoir 4

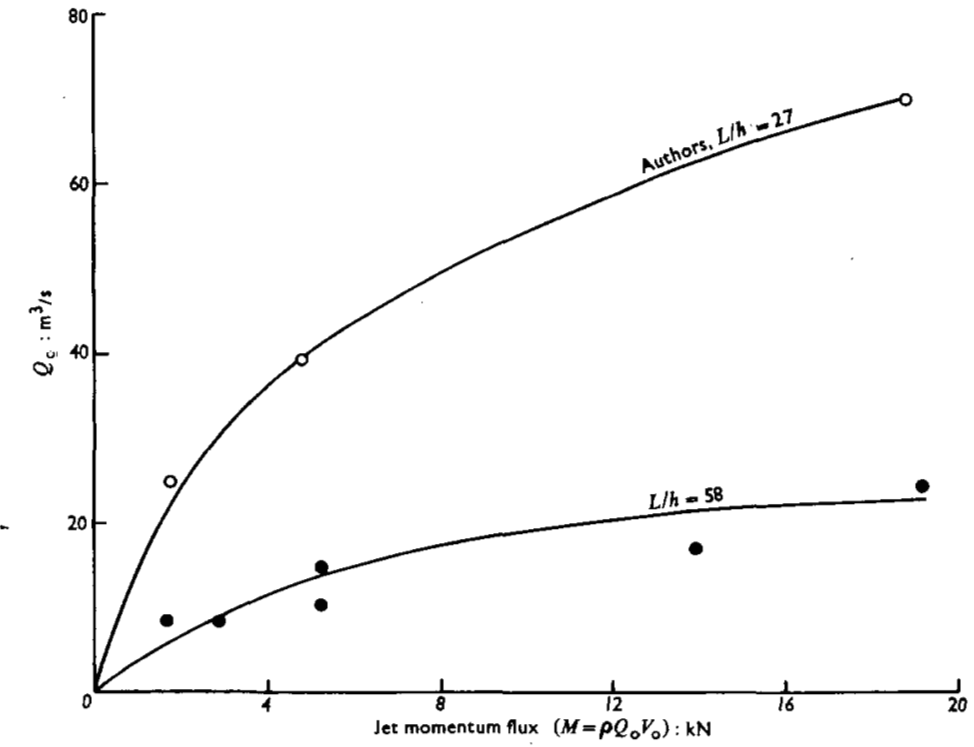

Fig. 30. Variation of circulating discharge with jet momentum flux 


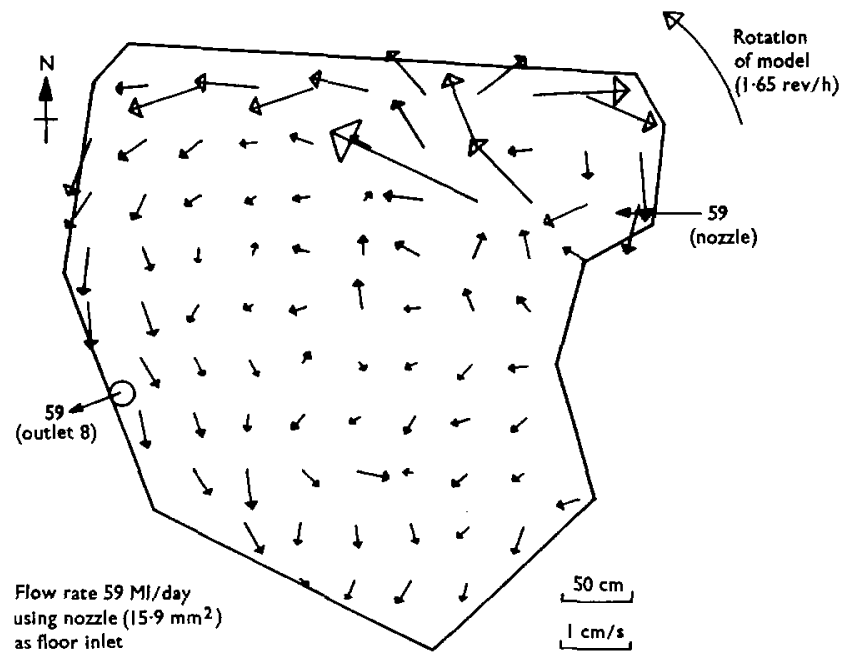

Fig. 31. Depth-averaged velocity field for reservoir 4 with rotation of the model

Paper. This may well be due to our measurement of depth-averaged velocities as compared with surface measurements by floats. Alternatively, this difference may be further confirmation of the Author's conclusion $(\$ 80)$ that such models are very sensitive to exaggeration of the vertical scale, as our model has only half the exaggeration of the main model in the Paper. This type of scale effect is also apparent when comparing the circulating flows in the models in Fig. 30. Our results give a lower circulating flow than those of the Paper, again probably because of the effect of using a different vertical exaggeration.

90. One factor influencing the motion of large masses of water not mentioned by the Authors is that of the Earth's rotation. In the case of the prototype, velocities of the order of $1 \mathrm{~cm} / \mathrm{s}$ could be induced, which are comparable with some of the smaller velocities measured. We were fortunate in being able to rotate our model and hence produce the flow pattern shown in Fig. 31, which corresponds to the non-rotating model in Fig. 28. As would be expected the effect of the rotation is small in the regions of high velocity but appears to have important consequences in regions of low velocity such as the south-east corner. As these slow-moving areas are of considerable importance in reservoirs it would appear to be desirable to take account of the Coriolis effect in reservoir models whenever possible.

91. It is noticeable from the flow patterns in the Paper that the outlet has little or no effect on the circulation, which is a result that we have consistently noticed. One effect that suitable positioning of the outlet can help minimize is short-circuiting, i.e. flow of water directly from inlet to outlet. It would seem that from this point of view. the outlet in reservoir 4 was originally poorly sited; a position towards the centre of the reservoir might have been more effective.

92. The results in the Paper using multiple jet inlets are interesting. Clearly the circulation is increased (Fig. 11), as would be expected with a higher net momentum input, producing a complex flow pattern with several strong gyres. The time taken for complete mixing would thus be reduced considerably and could be significant if a perfectly mixed system is desired. However, in such a system it might be difficult to avoid short-circuiting other than by having two outlets (one at the centre of each of the strongest 
gyres), and such an arrangement, with the expense of additional jets, could prove to be an uneconomic means of improving the water quality in an existing reservoir.

\section{Brigadier C. C. Parkman, Ward, Ashcroft and Parkman}

The Authors' investigation of the use of pumped inlet arrangements is very thorough and is an example to those who would tackle such scale model studies.

94. The background to this study indicates the desire of the water authority to ensure that their distribution system is free from pollution risk. The two open reservoirs, situated on the edge of the supply area, balance the infiow of treated water from the long aqueducts. They also provide an emergency reserve should there be an upstream aqueduct failure or treatment problem, or indeed temporary pollution of source water.

95. However, as they are uncovered they are susceptible to algal growth and bird pollution. The aim of the new works (now under design) at the site is therefore to provide a covered reservoir for the general throughput and to install treatment facilities to enable the existing storage to be retained. The operation and necessary flexibility of these treatment works is, of course, dependent on the water quality from the open reservoirs and therefore the model investigation was instituted to provide information on the present circulation patterns, range of residence times and methods of preventing any still water pockets.

96. As is the case with many reservoirs, they are on local high ground which is windswept for most of the year. The study confirms that in these shallow depths the wind causes extensive natural mixing.

97. For those quiescent days the laboratory studies indicate that pumped inlet jets will cause mixing. The design decision on whether or not to incorporate this additional facility on the existing inlets is dependent on assessment of the cost, frequency of use of the nozzle system and appreciation of the number of days per year when the throughput from the reservoirs should flow. The inlet nozzles will not be installed, at least initially.

98. These reservoirs are in many ways unique. It is unusual for such large reservoirs to be so shallow and for operation considerations to change so that the throughput required reduces significantly. They also now accept treated river water, whereas when they were installed the inflow was all direct from upland catchment. The scale model investigation undertaken on them will provide guidance for those contemplating new bankside storage, who will no doubt have the advantage of being able to select the reservoir geometry.

\section{Dr Ali, Mr Hedges and Dr Whittington}

In Fig. 9 the ordinates should be divided by $\sqrt{ } 50$. Mr Minton and $\mathrm{Mr}$ Robinson have made this correction in Fig. 30.

100. Dr Falconer has questioned our conclusion in $\$ 81$ that the mixing in reservoirs 3

Table 2. Comparison of relative dimensions of reservoirs

\begin{tabular}{l|c|c|c}
\hline & \multicolumn{2}{|c|}{ Diameter of reservoir } & Flow \\
\hline Falconer & 20 (two in Fig. 26) & $\begin{array}{c}6.5 \text { (one in Figs } 25 \\
\text { and 26) }\end{array}$ & $240 \mathrm{~m}^{3} / \mathrm{s}$ \\
\hline Authors & 2800 (two in Fig. 11) & $\begin{array}{c}550 \text { (two pipes at } \\
\text { outlet 8) }\end{array}$ & $\begin{array}{c}0.35 \mathrm{~m}^{3} / \mathrm{s}(30 \mathrm{MI} / \mathrm{d} \\
\text { in Fig. 11) }\end{array}$ \\
\hline
\end{tabular}


and 4 was markedly improved by the introduction of twin nozzle inlets. He suggests that the improvement is attributable to the increased inlet momentum flux rather than to the increased number of jets or their arrangement. Clearly, for a given inlet arrangement, mixing will generally increase with an increased inlet momentum, but we have become convinced that the manner in which the flow is introduced into the reservoir is no less important than the size of the momentum flux. By using two jets, the body of water in reservoir 4 was split into five main gyres (Fig. 11), whereas the original single inlet produced only two gyres (Fig. 6(b)). Although an increase in jet momentum for the original arrangement certainly caused an increase in circulating discharge $Q_{\mathrm{c}}$ (Fig. 9), a large, relatively stagnant area always remained near the reservoir centre. By splitting the reservoir flow into five gyres, the area of stagnant water was reduced. Consequently, in answer to Dr Falconer's question on the use of a single jet directed radially from point B15 (Fig. 1), we would expect that, all other things being equal, such an arrangement would give better mixing than the original single inlet 6 (which was effectively tangential to the reservoir boundary) but worse mixing than the twin inlets we recommended. The radial jet should be better than a tangential jet because it would produce two gyres of equal size (rather than one large and one small). However, relatively stagnant areas would still remain at the centres of these gyres. Fig. 32 is a time exposure for illuminated surface floats showing just such a radial jet discharging into a circular reservoir.

101. Dr Falconer is to be complimented on producing a mathematical model of flow in a hypothetical reservoir. However, it should not be supposed that this theoretical solution has any bearing on the real physical problems which we have tried to solve. His solution involves distortions of the inlet and outlet geometries. so large that the results cannot be applied to our problem (see Table 2). The principal consequence of this distortion appears to be that the outlets in Figs 25 and 26 have a large influence on the flow pattern. In our tests, and in those mentioned by Mr Minton and Mr Robinson, the outlets had very little effect.

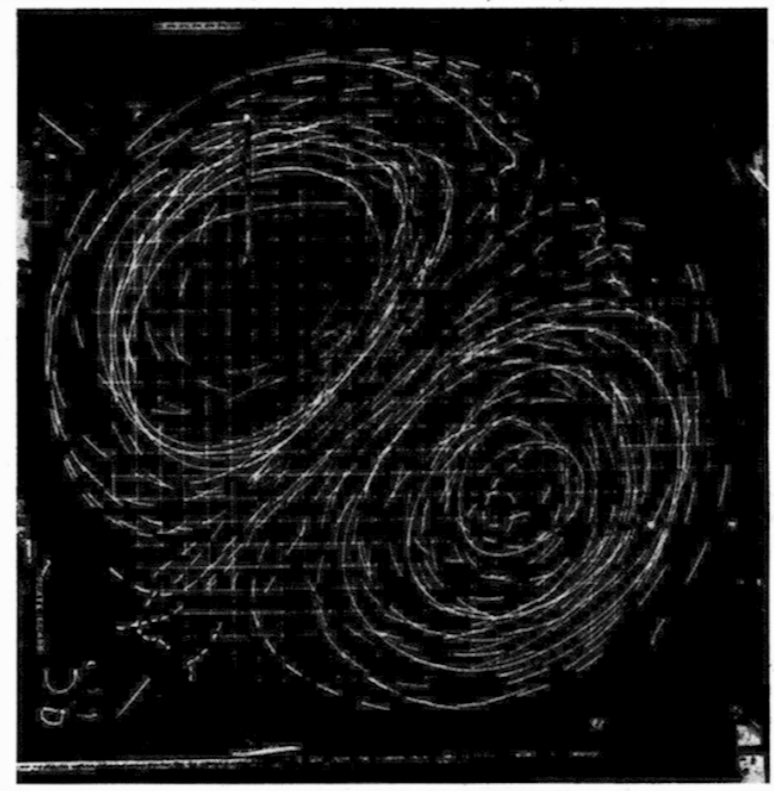

Fig. 32. Surface flows for a circular reservoir (after Pateman ${ }^{14}$ ) ; radial jet $L=3 \mathrm{~m}$, $d=2 \mathrm{~cm}, h=20 \mathrm{~cm}$, nozzle width $2 \mathrm{~mm}, Q_{0}=73 \mathrm{~cm}^{3} / \mathrm{s}$ 

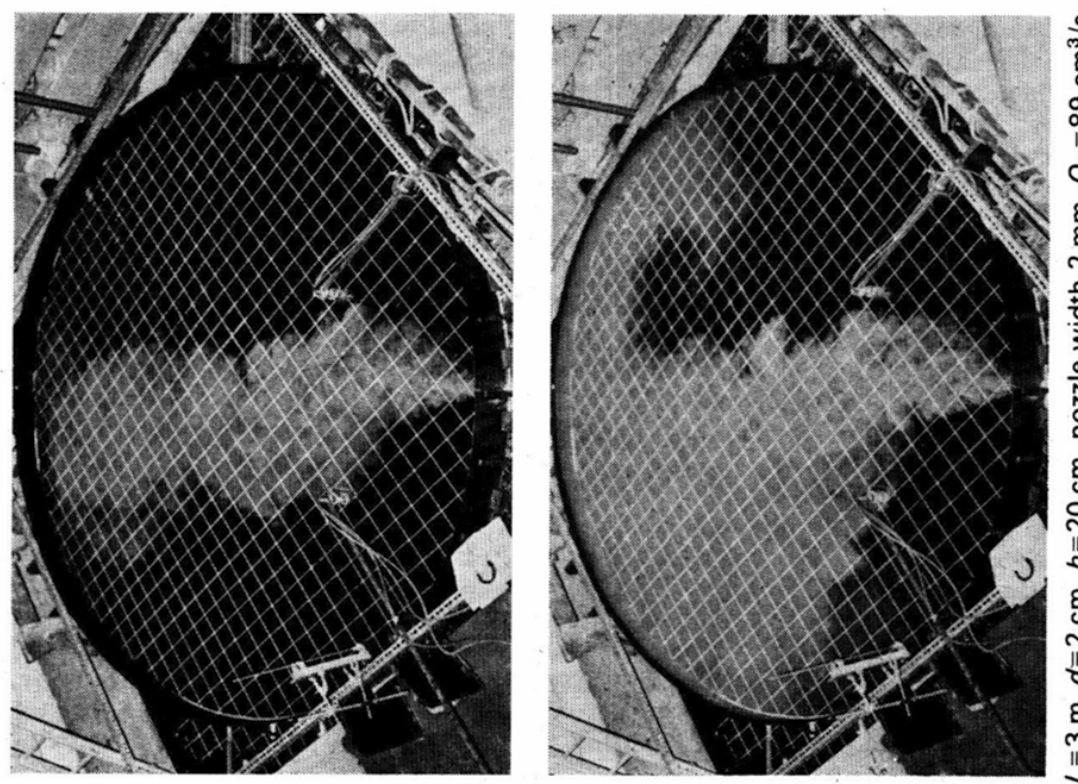

$\stackrel{\circ}{\circ}$

ํํำ

$\stackrel{n}{n}$

욜
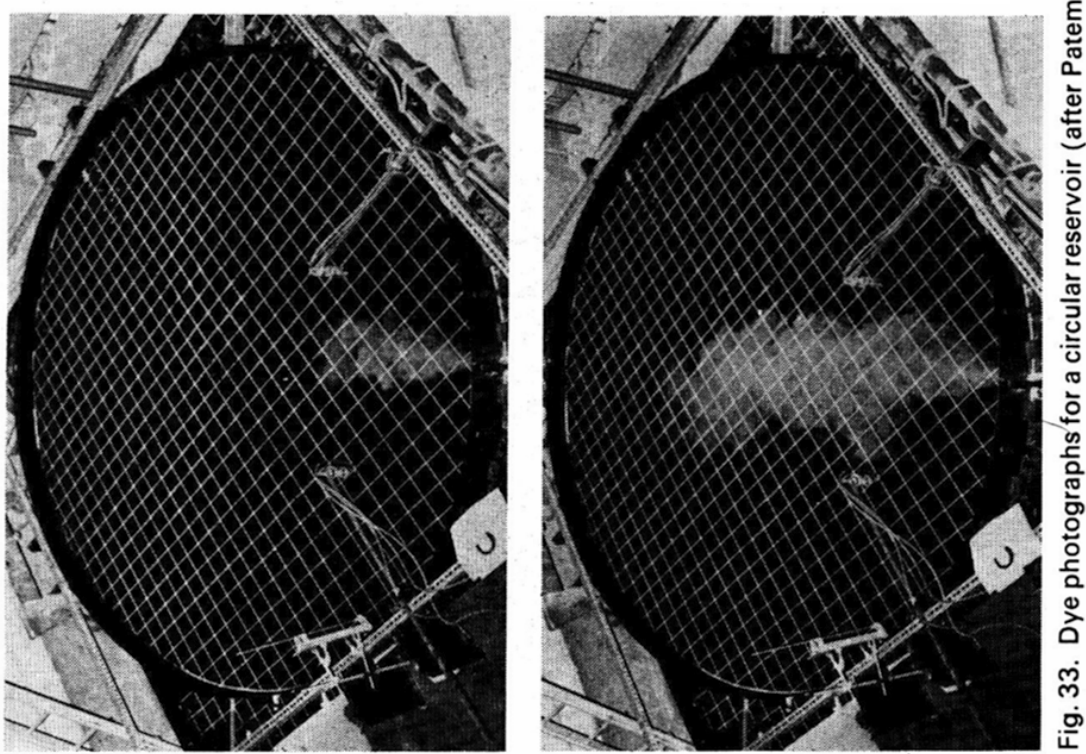

714

Downloaded by [] on [26/04/23]. Copyright (C) ICE Publishing, all rights reserved. 

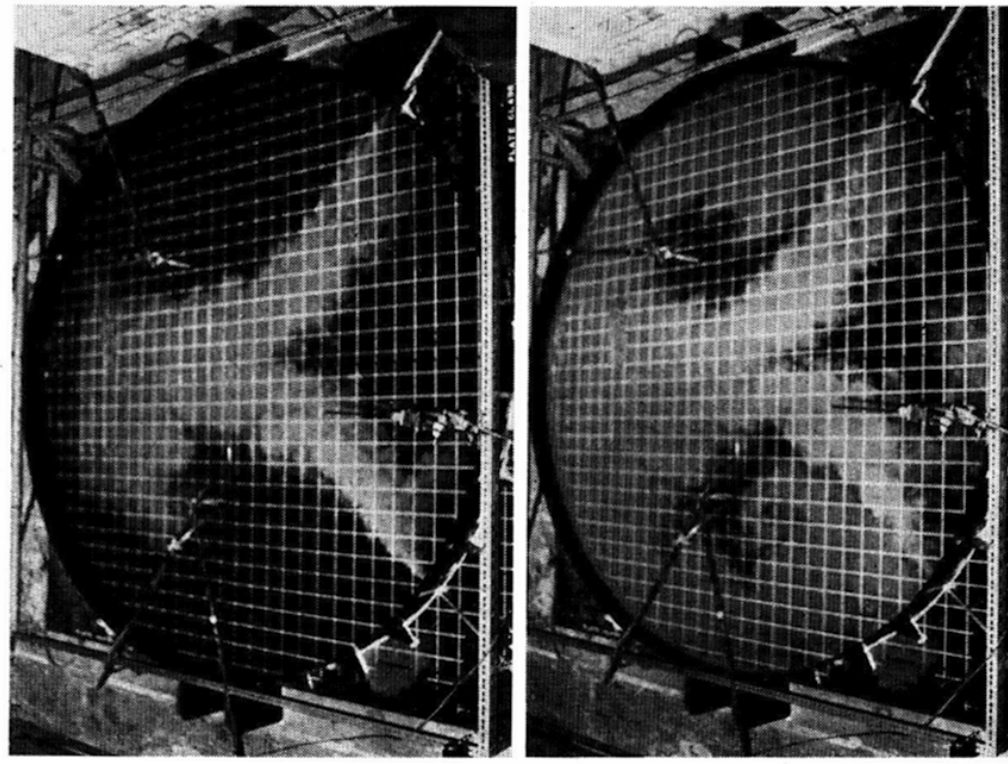

Eे

우

II

$s$

हू

N

II

E

E

m

II

$\checkmark$

ฮ

중

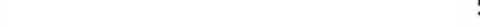

nn
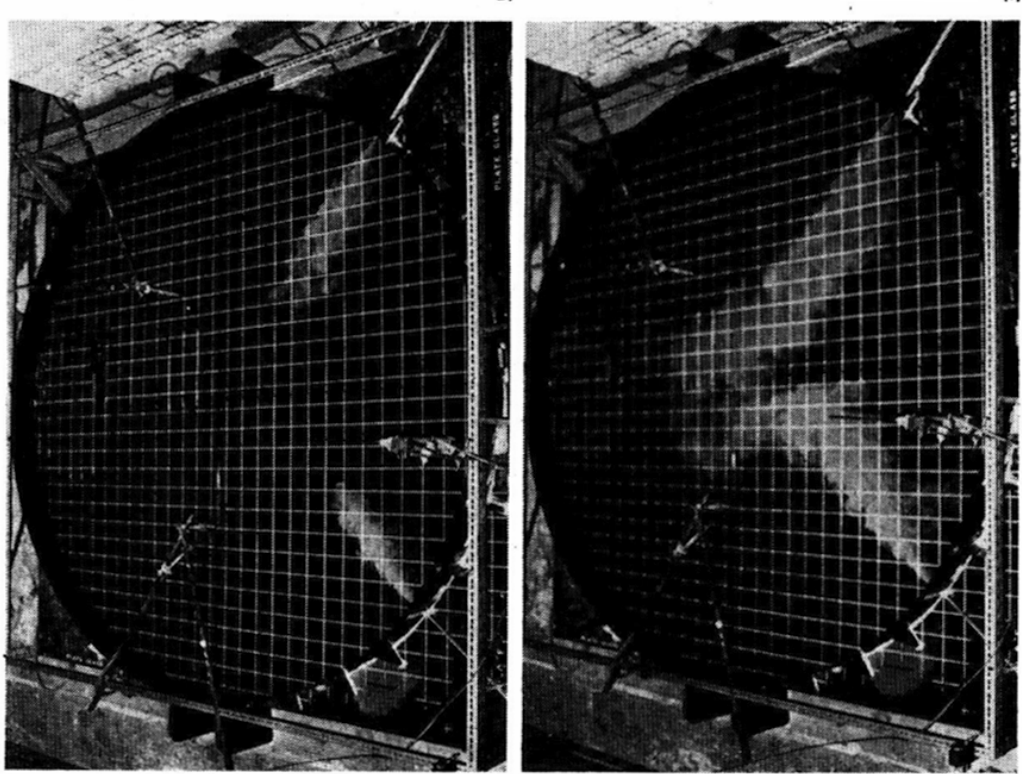

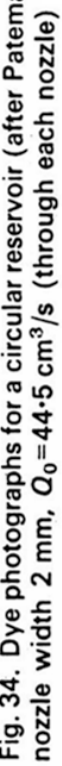


102. Figures $\mathbf{3 3}$ and $\mathbf{3 4}$ show two identical circular reservoirs, one with a single radial nozzle and the other with two perpendicular radial nozzles. All three inlets have the same cross-sectional area and the inflow into the two reservoirs is the same. It is clear that the mixing in the reservoir having two nozzles is superior to that having only one.

103. We are grateful to Mr Minton and Mr Robinson for the trouble they have taken to verify our results by building their own model of reservoir 4 . They suggest that the differences which they noticed in the flow in the south-east corner of the reservoir may be due primarily to the difference in vertical exaggeration. We agree, pointing out that the exaggeration causes changes in the aspect ratio, which we believe to be of primary importance. This can be seen by comparing Figs 6,27 and $21(L / h=24 \cdot 2,58$ and $93 \cdot 1$, respectively) and Figs $18(\mathrm{c})$, (b) and (a) $(L / h=25,53 \cdot 1$ and 125). Fig. 19 (for a tangential jet with a fixed Froude number) shows the influence of $L / h$ on the dimensionless circulating discharge. For the Liverpool and Imperial College values of $L / h$ of 24.2 and 58 respectively, the corresponding average values of $Q_{\mathrm{c}} / L \sqrt{ } K_{0}$ were 0.036 and 0.011 respectively, which confirms the trend shown in Fig. 19.

104. We were well aware of the desirability, in general, of attempting to reproduce geostrophic effects. Calculations using the concepts of Ekman ${ }^{10}$ and the solution by Welander ${ }^{11}$ indicated that, in the prototype reservoir 4 , geostrophic deflexions of currents might range from $1 / 2^{\circ}$ up to $3^{\circ}$, according to the value of eddy viscosity assumed..$^{10.12 .13}$

105. We agree with $\mathrm{Mr}$ Minton and $\mathrm{Mr}$ Robinson that geostrophic velocities of the order of $1 \mathrm{~cm} / \mathrm{s}$ might occur in the prototype. However, in view of the profound effect of vertical exaggeration on the circulation patterns, it seemed useless to rotate a distorted model. A marginal effect of this kind did not justify any attempt to rotate our undistorted (1/83.3) model.

106. The velocity values in Fig. 31 are distorted because the model was rotated at three times the generally accepted angular speed for reproducing geostrophic effects. This speed, as is well known, is governed by the reservoir latitude and the time-scale of the model. The latter is fixed by the horizontal and vertical scales. Thus any so-called geostrophic changes in Fig. 31 are exaggerated.

107. We are glad that $\mathrm{Mr}$ Minton and Mr Robinson confirm our findings that 'the outlet has little or no effect on the circulation'. Figs 6 and 8 show that $Q_{\mathrm{c}} / Q_{0}$ ranges from 37 to 103; thus in this model the flow through the outlet is less than $3 \%$ of the total. The results of $\mathrm{Mr}$ Minton and $\mathrm{Mr}$ Robinson covered values of $Q_{\mathrm{c}} / Q_{0}$ from 12 to 35 (less than $10 \%$ through the outlet). We agree that a centrally placed outlet might well have been preferable to the original layout with inlet 6 and outlet 8 (Fig. 1). However, repositioning of this outlet was not an option open to us.

108. Mr Minton and Mr Robinson implied that thorough mixing might not necessarily be the most desirable state. We agree. There might well be configurations, especially with a central outlet, in which more desirable retention times are achieved without complete mixing. However, in our case, as Brigadier Parkman has emphasized, the normal state of these shallow, windy reservoirs tends to be mixed, so that design for windless periods has been to maintain or enhance that state, rather than to establish a new and transient one. Design for ideal retention times, with partial mixing, would be more appropriate for a covered reservoir. Figs $10(\mathrm{~b})$ and 23 show how the danger of short-circuiting has been avoided by careful siting of the twin nozzles in relation to the fixed outlet.

109. We thank Brigadier Parkman for emphasizing the general utility of our work, whether or not the nozzles are eventually to be installed. He usefully outlines some of the practical difficulties encountered in the improvement and operation of these open, service reservoirs.

\section{References}

9. FALCONER R. A. Mathematical modelling of jet-forced circulation in reservoirs and harbours. PhD thesis, Imperial College, London, 1976. 
10. Ekman V. W. On the influence of the earth's rotation on ocean-currents. Ark. Mat. Astr. Fys., 1905, 2, No. 4.

11. WELANDER $P$. Wind action on a shallow sea: some generalizations of Ekman's theory. Tellus, 1957, 9, No. 1, Feb., 45-52.

12. Liggett J. A. and HaditheOdorou C. Circulation in shallow homogeneous lakes. J. Hydraul. Div. Am. Soc. Civ. Engrs, 1969, 95, HY2, Mar., 609-620.

13. LiNdH G. and Bengtsson L. Wind-induced circulation in a lake. Proc. 1st Int. Conf. Port \& Ocean Engng under Arctic Conditions. Technical University of Norway, 1971, 2, 893-908.

14. Pateman D. Research seminar, University of Liverpool, June, 1978. Unpublished work. 